\title{
Thyme Oil
}

National Cancer Institute

\section{Source}

National Cancer Institute. Thyme Oil. NCI Thesaurus. Code C107367.

The essential oil of Thymus vulgaris. Thyme oil is used for its antibiotic and antifungal activities. 